\title{
Case report: Effect of immunoglobulin on pain in Post-Polio Syndrome-Three case reports
}

\author{
Lars Werhagen ${ }^{*}$, Kristian Borg \\ Division of Rehabilitation Medicine, Department of Clinical Sciences, Karolinska Institutet, Danderyd University Hospital, \\ Danderyd, Sweden; ${ }^{*}$ Corresponding Author: lars.werhagen@ki.se
}

Received 8 February 2013; revised 11 March 2013; accepted 3 April 2013

Copyright (C) 2013 Lars Werhagen, Kristian Borg. This is an open access article distributed under the Creative Commons Attribution License, which permits unrestricted use, distribution, and reproduction in any medium, provided the original work is properly cited.

\begin{abstract}
Study design: Case reports. Setting: University hospital setting. Objective: To analyze the effect of intravenous immunoglobulin on neuropathic and nociceptive pain in three patients with PostPolio Syndrome (PPS). Materials and Methods: Three patients with PPS and pain who received treatment with $90 \mathrm{~g}$ Ivlg are described. Results: Before treatment one of the patients had pure neuropathic pain and the other two had a combination of neuropathic and nociceptive pain. There was no effect on pain in the patient with pure neuropathic pain and only effect on the nociceptive pain in the patients with a combination of neuropathic and nociceptive pain. Discussion: Pain is one of the most common symptoms in PPS. Previous studies have shown an effect on pain in PPS patients receiving Ivlg. The results of the present study point to that the effect on pain is limited to nociceptive pain and that there is no effect on neuropathic pain which leads to increased knowledge of characterization of responders of Ivlg treatment. Conclusion: Ivlg treatment treatment reduces nociceptive but not neuropathic pain in PPS patients.
\end{abstract}

Keywords: Post-Polio Syndrome; Pain; Immunoglobulin Treatment

\section{INTRODUCTION}

Pain is common in patients with Post-Polio Syndrome (PPS) and is present in a majority of patients [1-5]. The pain in PPS is in most cases nociceptive to its character but when neuropathic pain is present a concomitant disease must be suspected [3]. PPS patients in the western world have reached an age where concomitant neurological disorders more often occur. Thus, neuropathic pain is anticipated to increase in PPS patients the coming years. Furthermore, pain is more common among females than in males and the intensity of pain according to the VAS scale, as reported by PPS patients, is often high $[3,6]$. In a previous study we were able to show that treatment with intravenous immunoglobulin (IvIg) was effective and reduced nociceptive pain in seven out of ten PPS patients [7]. IvIg treatment, however, is costly and it is therefore of importance to thoroughly characterize responders for the treatment.

In this case report we describe three patients with PPS and pain of different origin, neuropathic and nociceptive, who reacted differently to IvIg. Thus, this gives more information to the background of the effect of IvIg in PPS, particularly for pain, and increase the knowledge of the different clinical features of responders on IvIg.

\section{METHODS}

A description of the patients appears in Table 1. PPS was defined according to the criteria of March of Dimes [8]. Before acceptance for treatment all three patients underwent a thorough neurological and general examination to confirm the PPS diagnosis. Medical investigation revealed no diagnosis constituting exclusion of treatment with IvIg in any of the patients. Immediately before and six month after treatment the patients underwent an examination by the physician responsible for the treatment, one of the authors. At the same time they were interviewed according to a specific questionnaire about the presence of pain, its intensity, character and localization, their social and working situation, walking aids, paresis and its localization and the presence of concomitant disorders.

Pain was classified according to the International Association for the Study of Pain (IASP). A pain was classified as neuropathic if present in an area with sensory disturbances to pin-prick and light touch and without relation to joint movements and/or infection. A pain was 
Table 1. Gender, age at polio infection, actual age, marital and working status, pares at its localization, the use of walking aids and concomitant diseases in the three PPS patients who underwent treatment with intravenous immunoglobulin (IvIg).

\begin{tabular}{ccccccccc}
\hline $\begin{array}{c}\text { Patient } \\
\text { number }\end{array}$ & Gender & $\begin{array}{c}\text { Age at } \\
\text { polio }\end{array}$ & $\begin{array}{c}\text { Age at } \\
\text { treatment }\end{array}$ & $\begin{array}{c}\text { Marital } \\
\text { status }\end{array}$ & $\begin{array}{c}\text { Working } \\
\text { status }\end{array}$ & Paresis & $\begin{array}{c}\text { Walking } \\
\text { aids }\end{array}$ & Concomitant disease \\
\hline 1 & Female & 1 year & 58 years & Married & Retired & Legs & No & Cervical disc herniation \\
2 & Female & 5 years & 65 years & Divorced & Retired & Legs & 2 crutches & Lumbar disc herniation \\
3 & Female & 5 years & 63 years & Married & Retired & Legs & No & Polyneuropathy \\
\hline
\end{tabular}

classified as nociceptive when aching in an area with signs of inflammation and painful joint movements were described. The intensity of the pain was measured with the Visual Analogue Scale (VAS) 0 - 100 before and after treatment. The patients received a total of $90 \mathrm{~g}$ of IvIg (Xepol, Grifols, Barcelona, Spain) during three consecutive days.

\section{CASE REPORTS}

\subsection{Case Number 1}

A 58-year-old married and retired woman. She contracted poliomyelitis at the age of one year. Initially she suffered from paresis and weakness of her left leg. She recovered and lived a normal life. Fifteen years previous to this study she experienced weakness of her legs. Neurological examination revealed a light to moderate paresis of both legs but she was able to walk unaided. She was diagnosed with PPS. In addition, she suffered from severe pain in her right arm. This pain was classified as neuropathic and the pain intensity before treatment was 80/100 (Table 2). Investigation with MRT revealed a cervical disc hernia.

She had no effect on her pain after IvIg treatment and was referred to a pain clinic.

\subsection{Case Number 2}

A 65-year-old retired and divorced woman. She contracted poliomyelitis at the age of 5 years. She was initially paretic in both legs but was, however, able to live a normal life and walked without aids. Around ten years previous to this study she became weaker in her legs and she was diagnosed with PPS. She walked with two crutches and for longer distances she used a wheel-chair. In 1983 she underwent surgery due to a disc hernia at L4/L5 level and was re-operated in 1993. She suffered from pain in her left leg classified as neuropathic and pain in her feet, back and arms classified as nociceptive. After treatment with IvIg the pain decreased from VAS 75 to 25 . Her neuropathic pain was only slightly decreased.

\subsection{Case Number 3}

A 63-year-old retired and married woman. She con- tracted poliomyelitis at the age of 5 years. She recovered fully but 20 years previous to this study she experienced problem with balance and weakness of the legs. However, she was able to walk without aids. At the post-polio outpatient clinic she was diagnosed with PPS. 2002 she was diagnosed with polymyalgia rheumatica, and polyneuropathy on a vascular basis. She underwent treatment with prednisolone. When examined she suffered from a pain in her lower legs classified as neuropathic and pain in back and thighs classified as nociceptive. She had undergone treatment with Gabapentin for her neuropathic pain without any effect. The intensity of pain according to VAS was 40 - 90/100 before and 15 - 40/100 after IvIg treatment. Six month after treatment her pain was classified as pure neuropathic pain.

\section{DISCUSSION}

The three patients of the present study demonstrate that IvIg was effective when pain with classified as nociceptive but not when classified as neuropathic. In all three patients a concomitant disease was present, in two patient's disc herniation and in the third patient the background to the neuropathic pain was polyneuropathy. This point to that the effect of IvIg in PPS is not primarily directed to pain but to the background to the pain. The background for the neuropathic pain is a direct effect on nervous structures either due to an external pressure as in disc herniation or due to metabolic factors as in polyneuropathy. However, the background for the nociceptive pain is not clear. Pain from joint and muscles is a common complaint in PPS patients. However, the pain has not been analyzed thoroughly. One possible background for nociceptive pain in PPS may be inflammation. An inflammatory process in PPS has been described both in cerebrospinal fluid and in peripheral blood [4,9-12]. IvIg has been reported to decrease the inflammatory process and in parallel a clinical effect including decrease of pain was found [4,10-14]. Furthermore, Melin et al. (K. Borg 2012, personal communication) showed an increase of prostaglandin antibodies in blood vessels of muscle in PPS patients which may be one underlying cause of muscle pain in PPS. Thus, one might speculate that the finding of the present study, a decrease of nociceptive pain as a result of IvIg treatment, is due to the dampen- 
Table 2. Pain its character and intensity according to the Visual Analogue Scale (VAS) before and after treatment with intravenous immunoglobulin (IvIg) in the three PPS patients.

\begin{tabular}{ccccc}
\hline Patient number & $\begin{array}{c}\text { Classification of pain before } \\
\text { treatment }\end{array}$ & VAS before treatment & $\begin{array}{c}\text { Classification of pain after } \\
\text { treatment }\end{array}$ & $\begin{array}{c}\text { VAS after } \\
\text { treatment }\end{array}$ \\
\hline 1 & Neuropathic & 80 & Neuropathic & 80 \\
2 & Nociceptive neuropathic & 75 & Neuropathic & 25 \\
3 & Nociceptive neuropathic & $40-90$ & Neuropathic & $15-40$ \\
\hline
\end{tabular}

ing of an inflammatory reaction. In order to confirm these studies with larger patient materials are required.

Besides the low number of patients reported in the present study this study can be critized in other ways. The classification of pain is difficult and the patients are in age when concomitant diseases are commonly found. However, the patients were before and after treatment examined by the same physician and interviewed according to a structured questionnaire and no other concomitant disorder was found. However, with the background of the results of this and other studies it is of importance to further analyze pain in PPS adequately and to further develop criteria for selection of PPS for treatment with IvIg based on clinical and molecular data.

\section{REFERENCES}

[1] Gonzalez, H., Olsson, T. and Borg, K. (2010) Management of postpolio syndrome. The Lancet Neurology, 9, 634-642. doi:10.1016/S1474-4422(10)70095-8

[2] Trojan, D.A. and Cashman, N.R. (2005) Post-poliomyelitis syndrome. Muscle Nerve, 31, 6-19. doi:10.1002/mus.20259

[3] Werhagen, L. and Borg, K. (2010) Analysis of longstanding nociceptive and neuropathic pain in patients with post-polio syndrome. Journal of Neurology, 257, 10271031. doi:10.1007/s00415-010-5456-0

[4] Farbu, E., Rekand, T., Vik-Mo, E., Lygren, H., Gilhus, N.E. and Aarli, J.A. (2007) Post-polio syndrome patients treated with intravenous immunoglobulin: A doubleblinded randomized controlled pilot study. European Journal of Neurology, 14, 60-65. doi:10.1111/j.1468-1331.2006.01552.x

[5] Willén, C. and Grimby, G. (1998) Pain, physical activity, disability in individuals with late effects of polio. Archives of Physical Medicine and Rehabilitation, 79, 915919. doi:10.1016/S0003-9993(98)90087-9

[6] Widar, M. and Ahlström, G. (1999) Pain in persons with post-polio. The Swedish version of the Multidimensional Pain Inventory (MPI). Scandinavian Journal of Caring
Science, 13, 33-40.

[7] Werhagen, L. and Borg, K. (2011) Effect of intravenous immunoglobulin on pain in patients with post-polio syndrome. Journal of Rehabilitation Medicine, 43, 10381040. doi:10.2340/16501977-0884

[8] March of Dimes. Post-polio syndrome: Identifying best practice in diagnosis and care. http://www.marchofdimes.com/downloads/PostPolio.pdf

[9] Gonzalez, H., Khademi, M., Andersson, M., Wallström, E., Borg, K. and Olsson, T. (2002) Prior poliomyelitisEvidence of cytokine production in the central nervous system. Journal of the Neurological Sciences, 205, 9-13. doi:10.1016/S0022-510X(02)00316-7

[10] Gonzalez, H., Khademi, M., Andersson, M., Piehl, F., Wallström, E., et al. (2004) Prior poliomyelitis-IvIg treatment reduces proinflammatory cytokine production. Journal of Neuroimmunology, 150, 139-144. doi:10.1016/j.jneuroim.2004.01.010

[11] Fordyce, C.B., Gagne, D., Jalili, F., alatab, S., Arnold, D.L., Da Costa, D., Sawoszczuk, S., Bodner, C., Shapiro, S., Collet, J.-P., Robinson, A., Le Cruguel, J.-P., Lapierre, Y., Bar-Or, A. and Trojan, D.A. (2008) Elevated serum inflammatory markers in post-poliomyelitis syndrome. Journal of Neurological Sciences, 271, 80-86. doi:10.1016/j.jns.2008.03.015

[12] Gonzalez, H., Khademi, M., Borg, K. and Olsson, T. (2012) Intravenous immunoglobulin treatment of the postpolio syndrome: Sustained effects on quality of life variables and cytokine expression after one year follow-up. Journal of Neuroinflammation, 9, 167. doi:10.1186/1742-2094-9-167

[13] Gonzalez, H., Stibrant-Sunnerhagen, K., Sjöberg, I., Kapanoides, G., Olsson, T. and Borg, K. (2006) Intravenous immunoglobulin for post-polio syndrome: A randomised controlled trial. Lancet Neurology, 5, 493-500. doi:10.1016/S1474-4422(06)70447-1

[14] Kaponides, G., Gonzalez, H., Olsson, H. and Borg, K. (2006) Effect of intravenous immunoglobulin in patients with post-polio syndrome-An uncontrolled pilot study. Journal of Rehabilitation Medicine, 38, 138-140. doi:10.1080/16501970500441625 